\title{
Analysis of Teachers' Voices of Learner Autonomy in EFL Online Learning Context
}

\author{
Sulistia Ningsih* Fazri Nur Yusuf

\begin{abstract}
Faculty of Language and Arts Education, Universitas Pendidikan Indonesia
\end{abstract} \\ *Corresponding author. Email: sulistia@upi.edu
}

\begin{abstract}
Autonomy of English language learners in a technology-supported learning environment has attracted much academic interest. However, learner autonomy in the Indonesian EFL setting has not commonly been considered as an important teaching and learning objective. Additionally, studies on teachers' voices of the emerging context of online learning platform over learner autonomy have not been well established. Therefore, the present study attempts to complement this line of research via a qualitative investigation of two EFL teachers. Interviews and classroom observation were used to collect the data about English teachers' voices regarding learner autonomy and learner autonomy-based practices. The finding suggests that the teachers perceived learner autonomy as the ability to learn independently and online learning helped them to promote learner autonomy. Teachers believe that learners should be able to make decisions about how they would like to learn, the activity they did, and what is involved in making decisions. With regard to learner autonomy-based teaching and learning practices, it was found that although the teachers desired to implement learner autonomy in their classroom context, and they used different strategies to promote learner autonomy. However, several factors such as learners' lack of autonomous learning experience, limited interaction, and insufficient proficiency in English became the constraints of developing learner autonomy in online learning classes. In this respect, it is important to provide learners with training to be autonomous and have a strong commitment to success in inculcating learner autonomy in an online classroom setting.
\end{abstract}

Keywords: Autonomous learning, e-learning, teacher's perception

\section{INTRODUCTION}

Researchers have attached much importance to learner autonomy especially in EFL and ESL contexts (Huang \& Benson, 2013). They attempt to reveal the fundamental ideas of learner autonomy and provide multiple suggestions to support the promotion of learner autonomy (Banditvilai, 2016; Tang, 2005; Tsang, 2020). However, an essential element in this line of research remains under-investigated. To date, few studies have examined how teachers perceive learner autonomy in their online classroom activity. The teachers' voices in relation to the actual online teaching-learning process and learner autonomy remain unclear. Although various studies on teachers' perception as in Borg and Alshumaimeri (2017), Dogan and Mirici, (2017), Wichayathian and Reinders (2015) have been conducted, they all tend to focus on face-to-face classroom interaction. How teachers make a judgment regarding learner autonomy in an online classroom setting has not been well established. Furthermore, research on technology and learner autonomy focuses more on fostering learner autonomy through the application of technology, but not on how teachers perceive the learner autonomy in the technology context itself. This represents a gap in literature because teachers' instructional behaviour influence students learning. Teachers' voices have an impact on the actual classroom practice because it significantly influences the ways in teachers to make professional judgments, interpret and engage with issues (Atkinson \& Rosiek, 2008). Thus, understanding teachers' voices unveils the knowledge of practice and experiences shaping how teachers make the judgment. In the e-learning context, what learner autonomy means to teachers thus influences how much and how teachers promote it. Besides, it indirectly affects the students' opportunity to be autonomous.

In comparison with learner autonomy in a face-toface classroom, an alarming issue is brought up by Borg and Alshumaimeri (2017). They argued that teachers control remains as a hallmark of acceptable teaching and 
learning classroom, therefore decision regarding the lesson and the assessment remains in the hand of teachers. On the other hand, the rapid advances in technology have greatly contributed to the emergence of new learning opportunities and offer a brand-new solution to create a more meaningful teaching and learning activity. But this also leads to another alarming notion. When the use of digital devices, online application and computer to study English as foreign language is becoming more common, conducting online class that promotes learner autonomy can be a challenging task for teachers with little background in this context. Unfortunately, whether learner autonomy is hindered or supported in an online learning context depends on the teachers themselves. Although online learning brings various benefits, the extent to which teachers promote learner autonomy in this emerging context of an online class is influenced by their voices. Therefore, it is highly essentials to reveal how teachers actually view learner autonomy in an online learning context

The specific areas of investigation addressed are as follow:

1) What are teachers' voices regarding learner autonomy principles in online learning contexts?

2) What is common learner autonomy-based teaching and learning practices conducted by teachers in online learning contexts?

\section{LITERATURE REVIEW}

\subsection{Learner Autonomy}

Literature studies on learner autonomy have raised various definitions. The formulation proposed by Holec (1981) has proved remarkably robust and remains the most widely cited. He defines learner autonomy as learners' ability to take charge of their learning. Variations on this definition abound. However, the definition proposed by Benson (2007) may be best to describe what learner autonomy is. He asserts that the construct of control is open to empirical investigation as control over learning has more variety of forms with reference to different dimensions of the learning process. In other words, autonomous learners are the ones who are capable of controlling different aspects of their learning process. Benson (2011) also elaborates that learner autonomy is a natural attribute of learners, but the extent to which autonomy is exercised and built is inhibited by the educational institution.

Learner autonomy can be viewed from several perspectives which are used to describe major versions of autonomy in language education circles. At least, there are four perspectives on learner autonomy: technical, psychological, political, and sociocultural (Benson, 2007; Dang, 2012; Oxford, 2003). The technical perspective focuses on the physical situation of learning. It considers learner autonomy as the independent learning situation where learner training is given by the teachers to the students. In the other words, the technical perspective conceptualizes learner autonomy as a situation that permits learners to decide what, when, and how to learn (Benson, 2007; Oxford, 2003). The creation of a learning environment with sufficient resources, wellprepared material, learning activities, and supporting technology is highly important so that learners can be responsible for their own learning performance. The psychological perspective deals with the learners' characteristics. The factors of autonomy are affected by attitudes, ability, learning, and style. The sociocultural perspective is concerned with mediated learning. It focuses on empowering students' learning experience. Political perspective deals with ideologies, access, and power structures. Although understanding the perspective is highly important, how teachers conceptualize learner autonomy should also be considered (Borg \& Alshumaimeri, 2017).

Benson (2011) categorized learner autonomy under three different dimensions. The first dimension, control over learning management, can be described in terms of behaviors involving language learning. It refers to learners' ability to plan, organize, and evaluate the learning. It deals with observable behavior related to where, when, and how to learn the language (Jing \& Benson, 2013). In the e-learning context, learners have shown different levels of control over their learning management (Ding \& Shen, 2019: Kizilcec, PerezSanagustin, \& Maldonado, 2017) the second dimension is control over cognitive processing. Benson (2011) emphasized on the management of attention, reflection, and metacognitive strategies. Similarly, Burkert (2011) argues that the cognitive dimension of learner autonomy, such as reflection and evaluation become the starting point and salient aspect of pedagogy. To facilitate control over cognitive processing, learners are encouraged to reflect upon their language learning (Little, 2007), the third dimension, control over learning content, refers to the situational dimension. It suggests the decisions made by learners to select language learning material that fits their learning goal.

\subsection{Online Learning}

Since the pace of technological change is accelerating, a new approach to teach language is being tried. In the language learning context, e-learning is enthusiastically explored and implemented in one form or another (Pham \& Tran, 2020). It is considered as a major force of change in the education system. It provides an opportunity for both teachers and students to explore language learning material and maximize the teaching and learning process. It functions as a vehicle 
for an advanced education which improves the quality of learning

E-learning is a general term covering various approaches that use multimedia technology and the internet (Clarke, 2004). E-learning also refers to language teaching and learning carried out using digital devices. It can be carried out using different kinds of tools and in a range of different contexts. Live broadcast, mobile video, audio, email, the web, and using tailor-made programs are just several examples of how e-learning can be applied (Cowie \& Sakui, 2013). E-learning includes an almost infinite array of tools ranging from websites for language learning to tailor-made online programs. Web 2.0 tools, such as blogs, wikis, podcasts even social media helps the learners and teachers to collaborate and interact in order to create a meaningful learning atmosphere. Not only does e-learning provide the combination of digital tools in the teaching and learning process, but it also offers the convergence of technology. Thus, it supports, creates, and even provides an extensive educational experience. Furthermore, e-learning is not only limited to use the contents of websites but also create content through the websites. The major benefit of e-learning is its flexible nature as a lesson can be carried out anytime and anywhere

\section{METHOD}

\subsection{Research Design}

In order to reveal the purpose of the research, a qualitative case study design was used in this present study. The case study design was chosen as the most appropriate design for this study under two substantive reasons. First, it provides an in-depth analysis in order to unravel the issue investigated in this study, namely teachers' voices of learner autonomy and their common teaching practice to promote learner autonomy in an online learning context. Second, the participants involved were two teachers in a specific institution, thus, their voices had a distinctive feature that could be compared with the theory and available literature.

\subsection{Research Participants}

Two English teachers who worked in a language institution were involved in the present study as participants. The participants' names are Tika and Maria (all names are pseudonyms). Both teachers have taught English for at least 4 years. The institution provided an elearning platform and Zoom Premium videoconferencing tool to conduct the learning process. Video conferencing via Zoom was done once a week with a 1.5 -hour duration time. Students were also given a weekly project in which they could exercise their knowledge and present their projects online. Furthermore, the institution provided an e-learning platform, Edmodo as well as shared Google
Drive to provide materials, quizzes, weekly projects, online videos, and assignments for the students.

\subsection{Data Collection}

Two instruments were used to collect the data. First, an interview with a semi-structured design was conducted to look into teachers' voices of learner autonomy in online learning context. Second, classroom observations were analysed to unravel learner autonomybased teaching and learning practices conducted by teachers in online learning context. Classroom observation sheet was adopted from observation sheet proposed by Ahmadianzeh, Seifoori, \& Tamjid (2018). Classroom observation via videoconferencing tool, Zoom, were conducted six times in which researcher acted as a complete observer. The procedures of the research started with interviewing the participants to see their perspective on LA and e-learning activities. Then their classroom observations were analysed to see how teachers promote learner autonomy. After data were gathered, overall result was analysed based on the research framework.

\subsection{Data Analysis}

The collected data were organized in such a way as to get a robust finding. The data were analysed by tallying each question to get general senses. Data from the participants were analyzed in several stages based on the theoretical framework. An analytical framework for describing and analyzing learner autonomy as proposed by Benson (2011), Borg and Alshumaimeri (2017), Oxford (2003) were used. Since the data were analyzed qualitatively, the raw data were coded, identified, and interpreted based on the key themes.

\section{FINDINGS AND DISCUSSION}

\subsection{Teacher's voices of learner autonomy in online learning context}

In this study, voices of English teachers were gained by conducting the interview and observing classroom activities covering four perspectives: technical, political, psychological, and social as has been indicated by Benson (2011), Oxford (2003), and Borg and Al-Busaidi (2017).

The findings revealed the teachers' voices in learner autonomy principles in the online learning context. Concerning the technical perspectives, it was found that teachers generally agreed that the online learning context could help learners to develop learner autonomy through independent study, learning outside the classroom context. Individual tasks involving the use of the internet led to better promotion of learner autonomy. 
Teachers also noticed that during online learning sessions, they had a bigger role to make sure the teaching and learning session would be effective. They agreed that online learning minimized their presence as teachers and led them to become the facilitator of learning. Tika stated that "We have our classes via Zoom meeting and the students' roles are more dominant here. Students can learn resource for themselves while I guide and motivate them so learning can be more effective"

Similarly, Maria stated that "In our online classes, we also discuss what needs to be learned. This way, students have a big responsibility and control towards their own learning"

In comparison with the face-to-face classroom, teachers thought that they had huge roles to control the learning process, and students were required to follow the instructions. However, during the online learning process, teachers agreed that the students' independence had a major proportion to create an effective teaching and learning activity. Teachers also believed that although the lessons were carried out virtually, learner autonomy did not mean learning without teachers. This is in line with Benson (2013) who mentioned that in the online learning context, the materials and access to language learning that was considered as a scare in the EFL setting are now accessible, therefore the barrier to autonomous language learning is lessened.

The psychological perspectives provided an overview of motivation, confidence, learning effectiveness, and learner-centeredness during online learning sessions affecting the success in learning English. In this perspective, teachers viewed online learning as two sides of a coin. Online learning could help learners to improve their language proficiency and provide a better learning experience. On the other hand, it might also be too tedious which demotivates learners.

Tika stated that "The students and I as teacher have shared Google drive. I always encourage them (learners) to check the materials provided there and I can see many students are eager to check the interactive videos and share what they know about it"

On the other hand, Maria stated that "To be honest, I let them decide what assignment or tools are suitable for them, and they show that they can independently think how to do it, but then we also have online quizzes and reading materials, but they always say that it (reading material) 's boring"

Furthermore, teachers also saw that learner autonomy emphasized on the students' ability to know and understand why they learned language. Teachers perceived that motivated language learners were more likely to develop autonomy than those who weren't especially in online learning context. Teachers saw that students' confidence and motivation gave crucial roles to determine the success in fostering learner autonomy and by using various online learning tools, learners were able to exercise their autonomous learning. This is in line with Clarke (2004) who mentioned that confidence was an important element in promoting independent learning through online classes or media. Online learning offered more learner-centered activity, therefore students with different language proficiency would be accommodated. Students were able to complete the tasks, review their lessons, and learn the material based on their learning pace which is in line with the ideas of learner autonomy. In regard to reflecting upon their learning, teachers agreed that the use of an online learning journal had helped learners to assess their own learning.

The political perspectives consisted of the right of learners in classroom settings. Teachers believed that freedom of choosing how the learners learn, selecting activities to work on, involving the learners to decide what to learn and allowing the learners to have voices in their learning could promote learner autonomy and online learning helped learners to do have a certain degree of freedom.

Tika stated that "I believe learner autonomy means letting my students select how they want to learn"

Maria stated that "Asking students to think about how they want to learn is the basic key of learner autonomy, and on Zoom, I could integrate many tools and websites so students can choose which one (learning strategy) is suitable for them"

Learners' voices and rights were commonly unexpected to exist in the traditional classroom. Teachers agreed that online learning provided a chance for the learner to select the activity that they wanted to work on and allow the learners to be involved in deciding what to learn. However, they also believed that the teachers had significant roles to allow learners to negotiate the learning process. This is also in line with Ahmadianzeh, Seifoori, and Tamjid (2018) who revealed that the application of learner autonomy also depended on the process-oriented learning techniques.

In regard to the socio-cultural perspectives, teachers believed that the online learning context had debunked the idea that learner autonomy could only be implemented in the western context.

Tika mentioned that "I believe that learners autonomy can be implemented in Indonesia. Also, via Zoom class, the students and I explored many things beyond just the ordinary classroom activity"

Maria stated that "I don't think learner autonomy is only suitable in USA, UK or any other western countries. Our students have the same capability to be autonomous, we don't need to be afraid"

Huang and Benson (2013) stressed similar point of view. They expressed that although learner autonomy was originated from Western context, its principles can 
be applied in all cultures as long as there is commitment to enact it.

\subsection{Common Learner Autonomy Based Teaching and Learning Practices Conducted by Teachers in Online Learning Context}

Teaching-learning practices were indicated by interviews and classroom observation. It showed that teachers had the desirability to promote learner autonomy in their online learning context. Promoting learner autonomy was also feasible to be conducted. Teachers showed the willingness to involve learners to choose the types of learning activity and also the assessment for their learning progress. Teachers provided a range of tools and methods to assess students' progress and the students were welcome to choose how they would like to be assessed. Both of the teachers allowed learners to decide to set their own learning plan as well as gave projects that allowed them to explore English outside the classroom context. The teachers agreed that they needed to create a fun learning environment and made the students comfortable in learning English, therefore, even with the little guidance from the teachers, students were still able to explore and learn independently.

Interestingly, both of the teachers used a variety of web tools to support the learning context. Each week, students did an online presentation using an interactive presentation tool. Topics were all decided by the students. Teachers also introduced online YouTube channels and posted the link on the classroom Google Drive so that the students would try to watch the videos. On the other hand, students showed their willingness to explore more than what the teachers had given and shared in the class. Thus, in the end, there would be a meaningful classroom interaction.

The implementation of online learning and the proliferation of learner autonomy also faced different challenges. It is found that it was rather difficult to be engaged students with a low level of proficiency. Although the classroom activities could cover students' differences and they were given the freedom to review the lesson, it was hard to build a strong interaction with students with a low level of proficiency. This is in line with the research from Hafner and Miller (2011), Lenkaitis (2019), Agonacs and Matos (2020) which revealed that although online learning could create an autonomous learning environment, it might also create disengagement. The students who aren't given a chance to negotiate the materials, especially if they have low level of proficiency may disengage themselves from the lesson.

The nature of online learning platform, such as Edmodo and also file sharing cloud such as Google Drive to store materials, quiz, related readings might also demotivate learners if teachers aren't able to use the platform correctly. The findings of the present study revealed that students selectively choose contents that are more useful and helpful for them.

\section{CONCLUSION}

The result of this study confirmed that learner autonomy could be promoted in an online learning context and it enabled them to foster learner autonomy. The teachers in this present study were able to share their roles with the students and let the students have a certain degree of autonomy. In terms of learner autonomy-based teaching-learning practice, it was revealed that the teachers had desirability to promote learner autonomy. Commitment is certainly the key to success in fostering learner autonomy.

\section{AUTHORS' CONTRIBUTIONS}

This study was conducted as the first author's thesis paper preliminary research. The authors confirm the responsibility for study conception, design, data collection, analysis and interpretation of the finding.

\section{ACKNOWLEDGMENTS}

The author would like to express gratitude to all the parties for their excellent participation with patience and passion in the present study

\section{REFERENCES}

Agonacs, N., \& Matos, J. F. (2020). Are you ready? Selfdetermined learning readiness of language MOOC learners. Education and Information Technology, 25(2), 1161-1179. https://doi.org/10.1007/s10639019-10017-1

Ahmadianzeh, B., Seifoori, Z., \& Tamjid, N. H. (2018). Exploring EFL teachers' belief about and practices of learner autonomy across experience and licensure. Innovation in Language Learning and Teaching, $\quad 14 \quad$ (2), 97-113. https://doi.org/10.1080/17501229.2018.1501694

Atkinson, B. M., \& Rosiek, J. (2008). Researching and Representing Teachers Voice(s). In A. Y. Jackson \& L. A. Mazzei (Eds.), Voice in Qualitative Inquiry (pp. 175-196). London: Routledge.

Banditvilai, C. (2016). Enhancing students' language skills through blended learning. The Electronic Journal of E-Learning, 14(3), 220-229.

Benson, P. (2007). Autonomy in language teaching and learning. Language Teaching, 40(1), 21-40. http://doi.org/10.1017/S0261444806003958

Benson, P. (2011). Teaching and Researching Autonomy. London: Pearson Education. 
Benson, P. (2013). Learner Autonomy. TESOL Quarterly, 47(4), 839-843. https://doi.org/10.1002/tesq.134

Borg, S., \& Alshumaimeri, Y. (2017). Language Learner Autonomy in a Tertiary Context: Teachers' Belief and Practices. Language Teaching Research, 23(1), 9-38. https://doi.org/10.1177/1362168817725759

Burkert, A. (2011). Introducing aspects of learner autonomy at tertiary level. Innovation in Language Learning and Teaching, 5(2), 141150.https://doi.org/10.1080/17501229.2011.57753 0

Clarke, A. (2004). E-Learning Skill. New York: MacMillan.

Cowie, N., \& Sakui, K. (2013). It is never to late: an overview of e-learning. ELT Journal, 67(4), 459467. https://doi.org/10.1093/elt/cct037

Dang, T. T. (2012). Learner autonomy: A synthesis of theory and practice. The Internet Journal of Language, Culture, and Society, 35(1), 52-67.

Ding, Y., \& Shen, H. (2019). Delving into learner autonomy in an EFL mooc in China: a case study. Computer Assisted Language Learning. Advance online publication. https://doi.org/10.1080/09588221.2019.1681464

Dogan, G., \& Mirici, I. H. (2017). EFL Instructors' perception and practices on learner autonomy in some Turkish universities. Journal of Language and Linguistics Studies, 13(1), 166-193.

Hafner, C. A., \& Miller, L. (2011). Fostering learner autonomy in English for science: a collaborative digital video project in a technological learning environment. Language Learning and Technology, 15(3), 68-86.

Holec, H. (1981). Autonomy and Foreign Language Learning. Oxford: Pergamon Press.

Huang, J., \& Benson, P. (2013). Autonomy, agency, and identity in a foreign language and second language education. Chinese Journal of Applied Linguistics,36(1),7-28. https://doi.org/10.1515/cjal2013-0002

Jing, H., \& Benson, P. (2013). Autonomy, Agency and Identity in Foreign and Second Language Education. Chinese Journal of Applied Linguistics, 36(1), 7-28. https://doi.org/10.1515/cjal-2013-0002

Kizilcec, R. F., Perez-Sanagustin, M., \& Maldonado, J. (2017). Self-Regulated Learning Strategies Predict Learner Behaviour and Goal Attainment in Massive Open Online Course. Computers and Education, 104 , 18-33. http://dx.doi.org/10.1016/j.compedu.2016.10.001

Lenkaitis, C. A. (2019). Technology as a mediating tool: videoconferencing, L2 learning, and learner autonomy. Computer-assisted language learning, 33

https://doi.org/10.1080/09588221.2019.1572018

Little, D. (2007). Language learner autonomy: some fundamental considerations revisited. International Journal of Innovation in Language Learning and Teaching, $\quad 1(1), \quad 14-29$. https://doi.org/10.2167/illt040.0

Oxford, R. L. (2003). Toward a more systematic model of L2 learner autonomy. In D. Palreyman, \& R. Smith (Eds.), Learner Autonomy across cultures. language education perspective (pp. 75-91). New York: Palgrave Macmillan.

Pham, Q. T., \& Tran, T. P. (2020). The acceptance of elearning systems and the learning outcome of students at universities in Vietnam. Knowledge Management \& E-Learning, 12(1), 63-84.

Tang, S. M. (2005). Investigating Malaysian distance learners' perceptions of their English proficiency courses. Open Learning: The Journal of Open, Distance and E-Learning, 20(3), 243256.https://doi.org/10.1080/02680510500298683

Tsang, A. (2020). Enhancing learners' awareness of oral presentation (delivery) skills in the context of selfregulated learning. Active Learning in Higher Education, 21(1), 39-50. https://doi.org/10.1177/1469787417731214

Wichayathian, N., \& Reinders, H. (2015). A teacher's perspective on autonomy and self-access: from theory to perception to practice. Innovation in Language Learning and Teaching, 12(2), 89104.https://doi.org/10.1080/17501229.2015.11032 45 